2016

\title{
Attitudes Toward Statistics Studies Among Students with Learning Disabilities
}

Orly Lipka

Haifa University, olipka@edu.haifa.ac.il

Itay Hess

Lewinsky College

Follow this and additional works at: https://digitalcommons.usf.edu/numeracy

Part of the Disability and Equity in Education Commons, Higher Education Commons, Online and Distance Education Commons, Science and Mathematics Education Commons, Secondary Education and Teaching Commons, Special Education and Teaching Commons, and the Student Counseling and Personnel Services Commons

\section{Recommended Citation}

Lipka, Orly, and Itay Hess. "Attitudes Toward Statistics Studies Among Students with Learning Disabilities." Numeracy 9, Iss. 2 (2016): Article 7. DOI: http://dx.doi.org/10.5038/1936-4660.9.2.7 


\title{
Attitudes Toward Statistics Studies Among Students with Learning Disabilities
}

\begin{abstract}
This study aims to examine the effectiveness of a support course to change attitudes toward statistics studies of post-secondary students who were diagnosed with learning disabilities (LD) and/or Attention Deficit Hyperactivity Disorder (ADHD). The participants were 22 students in a support course that was provided over a single academic term on a weekly basis. The design of the study was according to 'PrePost' comparison. The effects on attitudes toward statistics were examined quantitatively and qualitatively to provide a comprehensive methodology for the research purposes. Results suggest that the weekly support course model that was taught simultaneously to the on-line course may improve the attitudes toward statistics of at-risk students in three dimensions: affect, cognitive competence, and value. There was no measured improvement in the perception of difficulty. Analysis of the qualitative data provides complementary details on the roots of students' attitudes and the reasons for the changes. General implications for teaching statistics at the post-secondary level are presented and discussed as well as specific implications for students with LD and/or ADHD at the post-secondary level.
\end{abstract}

\section{Keywords}

post-secondary education, support, diversity, perception, pre-service teachers, mixed methods, statistics

\section{Creative Commons License} (c) (i) (8)

This work is licensed under a Creative Commons Attribution-Noncommercial 4.0 License

\section{Cover Page Footnote}

Orly Lipka is a Lecturer at the Learning disability department at the Faculty of Education, University of Haifa and a member at the Edmond J. Safra Brain Research Center. Her research focuses on supporting learners who are at risk of developing academic difficulties, supporting students at the post secondary education, the development of reading comprehension, and reading related process.

Dr. Itay Hess, through research and teaching, develops programs for the enhancement of the Quality of Life of students with special needs. His programs were evaluated by studies that were funded by the Israel Science Foundations (ISF) and by other Israeli Universities funds. In the previous year (2015) he published the first academic book in Hebrew ("Neither Darkness -nor Light") which offers professionals up to date knowledge to empower their support in students with blindness. 


\section{Introduction}

This study aims to examine the effectiveness of a support course to change attitudes toward the study of statistics among post-secondary students who were diagnosed with a learning disability (LD) and/or Attention Deficit Hyperactivity Disorder (ADHD). The ultimate goal of statistics courses is to help develop statistical thinking. In today's world, there is a growing need to understand statistics for research and practical applications. Ben-Zvi and Garfield (2010) discuss the need for statistical thinking in personal, academic, and professional life, citing an increase in the public use of statistics in advertisements, arguments, and advice of all kinds. They point to a growing need for the ability to use and evaluate statistics-based claims. In addition, Gal and Ginsburg (1994) discuss three main goals of postsecondary courses in the discipline. The first is to prepare students for more advanced statistics courses further in their education. The second goal is to prepare students for careers in which the handling of statistics is a daily procedure, particularly in science and research fields. Finally, an additional, non-professional goal is to enable students to deal with statistics in their everyday lives, including interpreting charts and graphs, evaluating statistical claims encountered in the media, and engaging in data-based decision making. Given this wide range of objectives, many students in colleges and universities take an introductory-level statistics course during their Bachelor-level studies.

Simply participating in a statistics class, however, does not guarantee that students will understand and use statistical thinking in practice. Butler (1998) argues that despite the fact that the number of adults who have completed a course in statistics has grown over the years, few make use of statistical methods or understanding over the course of their professional lives. Moreover, all of us have anecdotal evidence that people aren't using statistics outside their professions either. In order to achieve the ability to apply statistics well, a good grade in a statistics course simply isn't enough. Students who are able to apply their statistical knowledge understand the importance of statistics in their professional and personal lives, and they believe that they are able to understand and use statistics. In addition, successful students understand that after a single introductory course, they still do not know everything about the subject (Gal, Ginsburg and Schau1997; Garfield et al. 2002; Schau et al. 1995). Therefore, in order to make use of and benefit from statistical thinking, one's attitudes and personal beliefs are critical factors.

\section{Literature Review}

One important area of research documents the impact of these non-cognitive factors on students' achievement in statistics courses, demonstrating that the approach to statistics is an important variable in the learning process (e.g., Bondet al.2012; Evans 2007; Gal and Ginsburg 1994; Gordon 1995; Schau et 
al. 1995). Additional evidence from school-aged children measures the connection between one's perception of mathematics and academic achievement in that discipline. Eccles et al. (1983) study kindergarten through $12^{\text {th }}$ grade students and propose a multi-dimensional model that includes three main dimensions. The first dimension is the expectation for success measured by the student's level of self-efficacy regarding ability to succeed in mathematics. The second dimension is the difficulty of the task as perceived by the student. Finally, the value of the task capture show important the student perceives it to be. Their findings demonstrate a significant impact of these three perceptions on mathematics performance among schoolchildren.

Likewise, research at the post-secondary level demonstrates that attitudes toward statistics influence performance among students at that level. According to Gal and Ginsburg (1994), it is crucial to assess non-cognitive factors like students' attitudes toward statistics as well as previous experience with statistics and other mathematics courses, as these can have significant impacts on academic outcomes. Some of the factors enumerated in this seminal paper include motivation for future learning, self-concept/selfefficacy, appreciation for the relevance of statistics outside the classroom, mathematics anxiety, and baggage from negative academic experiences in the past.

In another study examining undergraduate students enrolled in introductory statistics courses, results demonstrated that pre-course and postcourse attitudes were both significantly correlated with the final course grade, while conceptions about statistics (a cognitive measure) were not (Evans 2007). These results demonstrate the importance of student attitude as a contributing factor in students' overall course experience. However, measuring the concept of attitude is a complex matter. Gal and Ginsburg (1994) stress the importance of capturing students' attitudes about statistics as accurately and completely as possible. They suggest that attention to attitudes should inform pedagogy with the aim of improving both course outcomes and the learning process. To this end, they suggest that while quantitative measures such as a Likert scale-based survey are valuable for assessing changes in attitude over the course of a term, qualitative tools can play an important role in truly understanding the sources of students' attitudes and beliefs about statistics.

Studies of academic emotions such as attitude and self-efficacy beliefs show that LD students very frequently have more negative academic emotions than their typically-learning peers (e.g., Klassen 2002; Multon, Brown and Lent 1991; Rubanet al. 2003; Tabassamand Grainger 2002). Ruban et al. (2003) study academic self-regulation (described as the activation of behaviors and emotions directed toward academic goals, including motivation and attitude) and compensation strategies among students with and without learning disability. They found that students with LD viewed less favorably and used less often various self-regulation and compensation strategies. These behavioral and attitude factors were significant predictors of students' GPA, 
suggesting that students with LD may be at increased risk of academic underachievement due to negative academic emotions and attitudes.

Additionally, the number of students with LD and/or ADHD in postsecondary education has risen steadily in recent years. In Israel, the Council for Higher Education reports that the number of university students with LD ranges from 1.5\% to 3\% (Finkelstein and Hellving 2005). For example, in the Open University of Israel the number of LD students rose from 500 in the 1996-1997 academic year to 750 in the 2000-2001 academic year (out of a total student body of 29,000). Similar trends have been reported in the U.S., where the rate of postsecondary students with a disability of any kind has tripled in the past 2 decades; LD is the fast-growing category, accounting for nearly $40 \%$ of disability students and approximately 1 in 25 students overall (Wolanin and Steele 2004). In Israel, the persistent increase in the proportion of students with LD prompted the 2008 passage of the Rights of Students with LD in Post-secondary Institutions, a law that enumerates the protected rights of students to equal access and appropriate academic accommodations.

A limited body of research has examined methods of influencing student attitudes toward statistics in post-secondary education. For example, Liau et al. (2014) study the effectiveness of different pedagogical methods in affecting attitudes and achievement outcomes in an undergraduate statistics course. The authors describe an experimental course designed to influence the attitudes of their students. They employed evidence-based pedagogical methods such as increased accessibility of the course instructor, use of hands-on activities, and collaborative learning in the context of the introductory statistics curriculum. The authors report attitudes before and after the course and summarize survey results regarding individual pedagogical methods' effects on student attitudes. The results indicate that certain methods not only positively influence students' attitudes, but they also positively correlate with achievement in the course. In related work, Gordon (1995) assesses student attitudes using openended questions, and through the qualitative analysis arrives at three principles that she believes can improve students' affective experience in statistics courses. First, the teaching of statistics requires a supportive environment in which students feel free to ask questions and take risks. Second, the teaching of statistics requires guidance so that students are able to apply what they know to new concepts. And third, the teaching of statistics is helped by the use of examples and imagery from personal experience.

A growing body of research on students with LD documents issues related to reading skills. However, work on LD in mathematics has progressed more slowly particularly at the post-secondary level. Somewhat more is known about primary- and secondary-school students. For instance, when examining school-aged students with different learning disabilities (mathematics disability (MD), reading disability (RD), both), a wide array of arithmetic difficulties were exhibited. Specific difficulties characterized specific groups. For instance, children with a combined MD and RD demonstrated numerical, counting, and arithmetical deficits, as well as deficits in digit span. Children 
with MD showed poor understanding of the order-irrelevance or adjacency counting principle, arithmetic-fact retrieval difficulties, and a high frequency of counting-procedure errors. Children with RD demonstrated difficulties in inhibiting irrelevant associations when retrieving arithmetic facts from longterm memory (Geary, et al. 2000). These difficulties persist to high school and probably to post-secondary education; however, research on this group of students is more limited.

Students with LD also demonstrate difficulties with specific mathematics problems. Word problems are challenging for students with LD because the skills required to solve these types of problems map onto the cognitive processing deficits that often affect this group of students (e.g., Fuchs et al. 2006). In addition, prior research has shown that students with LD are less likely to form mental representations (e.g., van Garderen 2006) and, when they do create such a representation, it is more likely to be a visual image of the problem context rather than a schematic representation that models the relationships among the quantitative elements of the problem (van Garderen 2006). Therefore, it seems likely that students with LD who experience difficulties with arithmetic are at greater risk to experience difficulties with statistics at the post-secondary level.

The relatively new field of statistics education research has recently explored strategies for effective teaching and learning of statistics. This mixed-methods study aims to examine effectiveness of a support course to change attitudes of LD and/or ADHD students in particular. In order to answer this question, we assess students' attitudes both quantitatively and qualitatively. In addition to more commonly employed quantitative measures, the study uses qualitative tools to examine the roots of students' attitudes, the different dimensions of students' attitudes, and students' perceptions of the effectiveness of various pedagogical components of the support course.

It is our central hypothesis that as a result of the weekly reinforcement of the support course, students will experience an increase in each of four dimensions of attitudes toward statistics (Schau et al. 1995), as detailed below:

1. Participation in the support course will lead to an improvement in students' affective experience of learning statistics.

2. Participation in the support course will lead to an increase in students' belief that they possess the cognitive and intellectual abilities required to understand statistics.

3. Participation in the support course will lead to an increase in the students' assessed value of the importance of statistics and its application to work and daily life.

4. Participation in the support course will lead to a decrease in students' perception of the difficulty inherent in learning statistics.

Additionally, the support course was designed using research-based pedagogical methods to the teaching of statistics. We hypothesize that at-risk students will indicate that these approaches are helpful components of the statistics support course. 


\section{Methods}

\section{Participants}

All study participants are third-year students training to be teachers. Each have been formally diagnosed with LD and/or ADHD and registered in the disability support center of the college. As an aggregate, students were diagnosed with difficulties in the following areas: language, attention, memory, writing, and organization of writing. As part of their third-year academic studies, the students were enrolled in an online statistics course that was offered during the spring semester and involved the completion of written assignments and a final examination at the end of the semester.

\section{Measures}

In order to assess attitudes toward statistics, we include quantitative and qualitative measures. First, we administered the Survey of Attitudes Toward Statistics (SATS - Schau et al. 1995). This tool consists of 29 items covering the four dimensions of attitudes toward statistics described above: affect, cognitive competence, value, and difficulty. Each item contains a statement about statistics, such as "It is easy to understand statistical formulas, and participants were asked to rate the extent to which they agree with the statement, on a scale of 1 (strongly agree) to 7 (strongly disagree). As reported by Schauet al. (1995) andChiesi and Primi (2009), the survey has high reliability. For the purposes of the present study, the survey was translated into Hebrew and further validated by two experts in the field. The 29 items in the survey were divided into the four attitude dimensions as follows:

1. Affect - Six items deal with students' subjective emotional experience of learning statistics. For example, "I enjoy taking Statistics."

2. Cognitive Competence - Eight items address students' self-assessment of their cognitive and intellectual competence to understand statistics. For example, "I have difficulty understanding statistics because of the way that I think.”

3. Value - Six items measure students' assessment of the value of statistics in professional and personal life. For example, "I use statistics in my everyday life."

4. Difficulty - Three items address students' assessment of the inherent difficulty of learning statistics. For example, "I think it is very difficult to understand statistical concepts.”

\section{Study Design and Procedure}

Diagnosed LD and ADHD students who were registered at the disability center at the college were contacted through the center and were offered the opportunity to participate in the statistics support program as a complement to their enrollment in the online statistics course. Of those, 30 accepted our invitation and enrolled in the support course through the disability center. Given our understanding of the special needs of this student subgroup, the institution did not believe it appropriate to deny support to any LD- or 
ADHD-diagnosed students and all the students that were registered at the support center. In addition, only a small number of invited students opted out of the support course. Therefore, it was infeasible to implement an experimental design with both treated and control groups (determined either by random-or self-selection). Instead, the four hypotheses were tested by comparing students' pre- and post-course scores on the four dimensions of the SATS survey instrument.

Participants in the support course enrolled voluntarily and only those who consented and completed the surveys were included in the study. Of the 30 students enrolled in the support course, 22 agreed to complete the SATS instrument at the start of the course. In one of the first meetings of the support course during the spring semester, the students were informed of the study and presented with an explanation of the procedure by the research assistant. Those who consented to participate completed the SATS during the final 10 minutes of one of the first lessons. At the end of the spring semester, upon completion of the support program, the same 22 students completed the SATS a second time. Prior to the administration of the pre-test, students received two stickers with ID numbers and were asked to stick one on the pre-course test and to save the second for the post-course administration.

In addition, all of the 22 students who had completed both the pre-course and post-course administrations of the SATS were invited to participate in the qualitative portion of the study that was conducted upon completion of the course. Ten agreed to do so. Two research assistants met individually with each of the students in a quiet room and conducted the in-depth semistructured interview. These students answered open-ended questions designed to learn about students' past and present attitudes toward statistics and toward the support course model. As described by Gal and Ginsburg (1994), openended interview questions are often better able than Likert-scale questions to capture the origins of students' attitudes and thus may more effectively inform course improvement. In this light, the qualitative data can be viewed as an indepth complement to the quantitative (SATS) data, providing insight into the roots of the participants' attitudes along the four dimensions delineated by the SATS, as well as students' perceptions of the effectiveness of the various pedagogical components of the support course. (Interview questions can be found in the results section below.) All interviews were recorded and transcribed by the research assistants, who then analyzed the responses.

\section{The Support Course}

All of the participants in our study completed an online statistics course. The associated support course was conducted for the length of the semester at a fixed time once per week. Attendance in the program was mandatory for those enrolled, in accordance with the attendance policy for all courses at the college. The support course was held in two separate groups to maintain relatively small class sizes (fewer than 15 students per group). Both groups were led by the same lecturer, and both groups received the same level and 
amount of support. A total of 14 weekly sessions took place during the spring semester. Each session of the support course was structured congruently with the corresponding lesson of the regular online statistics course.

Evidence-based pedagogical methods (National Research Council2000, 2005) and pedagogical approaches driven by post-secondary statistics research (e.g., Gordon 1995 and Liau et al. 2014) were implemented in the support course. The following is a description of the general structure of the support course, highlighting its unique characteristics:

1. At the beginning of each session, the objectives of the lesson were defined.

2. During the course of each session, the lecturer made use of the whiteboard instead of using prepared slides. The instructor made use of numerous examples, real-life situations and visual aids to emphasize the real-life applications of the statistics course content.

3. Course material was read and abstract concepts were clarified through the use of more concrete concepts. Scaffolding was given so that students were able to apply what they know to new concepts.

4. The instructor employed hands-on activities to enhance instruction. The lecturer frequently made use of leading questions and examples. Students were also given questions to solve on their own, and then subsequently the solutions were broken down into steps on the whiteboard at a slow enough pace to ensure that the students were able to follow along and fully transcribe the solutions in their course notes.

5. At the beginning of each session, connections to the previous lesson were made. At the end of each session, connections to the following lesson were made.

6. Online course assignments were not completed during the weekly support course sessions; however, the lecturer explained and described the assignments, and emphasis was placed on the importance of working through each task when it was assigned.

7. The instructor was directly accessible throughout the support course and created and fostered a supportive environment in which students could feel free to ask questions and take risks. Throughout the full length of the support course, the lecturer was available by email for questions and special requests, and in isolated instances provided additional assistance to students outside of the weekly sessions.

\section{Results}

Because we were concerned that translation of the original SATS items into Hebrew may have created ambiguities in some items that reduced reliability, we examined student responses to each item to discern whether elimination of translated items would improve the functioning of the instrument. We found six items associated with two dimensions (value and difficulty) that appeared to reduce reliability. Table 1 shows the results of reliability testing of the 29 items to the four dimensions of the questionnaire, after removing items that decreased reliability and reversing items for which high-number responses reflect negative attitudes. 
Table 1

Coefficient of reliability test results (Cronbach's alpha) for the four dimensions of the Survey of Attitudes Toward Statistics (SATS)

\begin{tabular}{|c|c|c|c|c|c|c|}
\hline & \multirow[t]{2}{*}{ Dimension } & \multirow[t]{2}{*}{ Items } & \multirow{2}{*}{$\begin{array}{l}\text { Removed } \\
\text { Items }\end{array}$} & \multirow[t]{2}{*}{ Reversed Items } & \multicolumn{2}{|c|}{ Cronbach's Alpha } \\
\hline & & & & & Pre & Post \\
\hline 1 & Affect & $1,2,11,14,15,20,21$ & & 1,15 & 0.8 & 0.77 \\
\hline 2 & $\begin{array}{l}\text { Cognitive } \\
\text { Competence }\end{array}$ & $3,4,6,17,22,23,26,28$ & & $4,17,23$ & 0.75 & 0.79 \\
\hline 3 & Value & $5,7,8,10,13,25$ & $12,16,19$ & $7,8,13$ & 0.66 & 0.72 \\
\hline 4 & Difficulty & $20,27,29$ & $9,11,18$ & & 0.65 & 0.68 \\
\hline
\end{tabular}

The final columns of Table 1 report Cronbach's Alpha on the resulting, reduced survey instrument on both the pre-course and post-course tests, showing that the instrument is more or less equally reliable in both administrations

In order to test the hypotheses articulated above, we conducted paired $t$ tests between the pre- and post-course Scholastic Assessment Test (SATS) average measures for each of the four dimensions. Results are presented in Table 2.

Table 2

Results of paired t-tests between pre- and post-intervention SATS mean measures for each of the four dimensions: Affect, cognitive competence, value, and difficulty. $\mathrm{N}=22$

\begin{tabular}{|c|c|c|c|c|c|c|c|}
\hline Dimension & $\begin{array}{l}\text { Pre-test } \\
\text { Mean (SD) }\end{array}$ & $\begin{array}{l}\text { Post-test } \\
\text { Mean (SD) }\end{array}$ & $\begin{array}{l}\text { Mean } \\
\text { Difference }\end{array}$ & $\begin{array}{l}\text { Pooled } \\
\text { Standard } \\
\text { Error }\end{array}$ & $\begin{array}{l}\text { Standard } \\
\text { Error of } \\
\text { Mean } \\
\text { Difference }\end{array}$ & $\begin{array}{l}\text {-score } \\
(\mathrm{df}=21)\end{array}$ & $\begin{array}{l}\text { Cohen's } \\
\text { d }\end{array}$ \\
\hline Affect & 3.15 (1.3) & $4.80(.51)$ & 1.65 & 1.37 & .29 & $5.6^{* *}$ & 1.2 \\
\hline $\begin{array}{l}\text { Cognitive } \\
\text { Competence }\end{array}$ & $3.07(.92)$ & $4.09(.75)$ & 1.02 & 1.15 & .25 & $4.1^{* *}$ & .9 \\
\hline Value & $3.72(.9)$ & 4.37 (.6) & .65 & 1.18 & .25 & $2.53^{*}$ & .55 \\
\hline Difficulty & 3.55 (1.33) & $4.08(1.25)$ & .53 & 1.72 & .37 & 1.44 & .307 \\
\hline
\end{tabular}

The average post-course measure of students' affective experience of learning statistics was significantly higher than the corresponding pre-support course measure $(t(21)=5.6, \quad p<.01 ; \quad C o h e n ' s \quad d=1.2)$. Similarly, students' selfassessment of their cognitive and intellectual competence to understand statistics was significantly higher after the support course $(t(21)=4.1, p<.01$; Cohen's $d=.9$ ). In addition, the average post-support course measure of 
students' assessed value of the importance of statistics and its application to work and daily life was significantly higher than the corresponding presupport course measure $(t(21)=2.53, p<.05$; Cohen's $d=.55)$.

Interestingly, while the students indicated greater confidence in their capacity to do the work, their attitudes about the difficulty inherent in learning statistics changed little. The post-course scores showed only a small reduction in student assessment of the material's difficulty, a change that was not statistically significant $(t(21)=1.44, p=.16$; Cohen's $d=.307)$, The students continued to perceive statistics as a difficult subject even after completing the support course.

The second part of the study was qualitative in nature, using a student interview model (implemented upon the completion of the course) similar to that discussed by Gal and Ginsburg (1994) and employed by Gordon (1995).Nine out of the ten students who participated in the interviews had not studied statistics during high school. Most of the participants (eight) indicated that their previous statistics knowledge was quite limited. Two out of the ten mentioned that the field is related to data processing. Regarding their feelings about learning statistics, the general picture emerging from the responses of seven out of ten participants was one of dread and worry stemming from talk and rumors among their peers that many students fail the course. About seven of them reported that their perception was reinforced by stories from friends who had taken the course in the past. $J^{\prime}$ described her source of knowledge and ideas about statistics:

"Everything I knew came from friends who took statistics in university and how difficult they said it is. This is what made me feel stressed and anxious.”

Next, in order to examine the support course's impact on students' attitudes toward statistics, we asked them in the post-course interview whether they think that their participation in the support course likely improved students' positive feelings regarding statistics, developed students' faith that they possess the cognitive abilities necessary to understand statistics, increased students' level of awareness of the importance of statistics, and diminished the degree to which they perceive the subject matter as difficult.

With regard to whether they had positive feelings about statistics after participating in the support course, all of the interviewees responded affirmatively. The benefits of the program that were mentioned included individualized learning, personal attention, and immediate response to questions whenever they arose; the advantage of classroom instruction over the standard online course; the support and assistance students received that facilitated the learning process; and the added benefit of cooperating with peers at similar levels of ability. $C^{\prime}$ gave the following response:

"In my opinion, yes. When learning in a classroom setting (and not in an online course) it is much easier to understand the material. During the lessons, there were many explanations and practice exercises, and we saw that it's not as difficult and scary as we had heard before the course. Additionally, in the reinforcement program, 
there is continuous communication between the lecturer and the students, both during the lessons and via computer, and that really made things easier."

Students were then asked whether participating in the program can improve students' faith that they possess the cognitive and intellectual abilities necessary to understand statistics, and again all of the interviewees responded affirmatively. They pointed out that the close support and individual attention students receive can strengthen their self-confidence and trust in their ability to succeed. Additionally, the interviewees noted that the thoroughness with which the program delves into the course material can improve students' comprehension, encourage them to try hard, and strengthen their sense that they can succeed. $B^{\prime}$ commented:

“At first, students with LD are especially nervous because they know that statistics is a difficult subject. But when there is close, personal attention, it is easier and there are more successes, and then the students are able to believe in their abilities. I think that this can lead a student to have more faith in himself. However, with each success in the course, his confidence in his abilities [are] strengthened."

When asked whether participation in the program is likely to bring about an increase in the level of awareness of the importance of statistics and its usefulness in professional and everyday life, the responses were mixed. Four students reported that participation in the program would help in work, everyday life, and also in other statistics courses. A' commented:

"In my opinion, yes, but [the impact of the program] is very individual. For me, the examples during the lessons were from our professional world as educators, at work and also a bit from our everyday lives. I understood that I can make use of statistics in my own life - as a teacher of special education and science - and I understand the importance of the subject."

Five others indicated that they do not see the importance of statistics in their everyday life. $I$ ' indicated that,

"I do not see statistic[s] as a relevant subject to my life."

In addition, students' comments were analyzed for descriptive words and phrases demonstrating attitudes toward statistics. Organized according to the four dimensions - affect, cognitive competence, value, and difficulty (Schau et al. 1995) - Table 3 presents words and phrases students used to describe their thoughts and experiences. The final column of the table notes whether the comment reflects an attitude perceived before ("pre”) or after ("post") completion of the course.

A preliminary analysis of interviewees' comments reveals several interesting patterns that, taken in concert with the quantitative results discussed above, reveal a more detailed picture of how the support course influenced students' attitudes toward statistics. First, student attitudes show a pattern of development from primarily negative attitudes (that are generally rooted in others' experiences) to primarily positive attitudes grounded in their own successes during the course. The vast majority of participants had little or no prior experience learning statistics, and many students mentioned feeling 
scared or anxious because they had heard that statistics was a very difficult course with a high rate of failure. This may explain why many of the interviewees' comments about their attitudes prior to the course included the common themes of fear and the high degree of difficulty of the subject. It is telling that virtually all comments that contained references to students' affective attitudes toward statistics upon completion of the course either negated their previous fearful attitudes or spoke instead of relief and increased self-confidence. For example, $B$ ' described her perception:

"Participating in the support course changed my perception. I first came with fears, but during the course of the lessons, as I understood the material and succeeded in solving problems, I saw that I have the ability to learn statistics, and that's a good feeling."

Table 3

Classification of words and phrases according to each of the four dimensions: affect, cognitive competence, value, and difficulty

\begin{tabular}{|c|c|c|}
\hline Attitude Descriptor & Dimension & Time \\
\hline Frustration & affective & pre \\
\hline Scary & affective & pre \\
\hline Stressed & affective & pre \\
\hline Anxious & affective & pre \\
\hline Fears & affective & pre \\
\hline Nervous & affective & pre \\
\hline Dread & affective & pre \\
\hline Worry & affective & pre \\
\hline Friends said it is very difficult & difficulty & pre \\
\hline Stats is a difficult subject & difficulty & pre \\
\hline I have the ability & cognitive competence & post \\
\hline Belief in one's abilities & cognitive competence & post \\
\hline More faith in oneself & cognitive competence & post \\
\hline Increased confidence & cognitive competence & post \\
\hline Need for creative thinking & cognitive competence & post \\
\hline Requires openness to learning & cognitive competence & post \\
\hline $\begin{array}{l}\text { Requires deep understanding of purpose rather than } \\
\text { just mechanical computations }\end{array}$ & cognitive competence & post \\
\hline I can make use of statistics & value & post \\
\hline I understand the importance of the subject & value & post \\
\hline Not much connection between stats and other subjects & value & post \\
\hline $\begin{array}{l}\text { My success in stats isn't related to how much I'll } \\
\text { succeed in other subjects }\end{array}$ & value & post \\
\hline Stats is vital to research & value & post \\
\hline $\begin{array}{l}\text { Stats is also important in different areas of everyday } \\
\text { life }\end{array}$ & value & post \\
\hline Broad applicability of statistics skills & value & post \\
\hline Of no assistance to studies in other fields & value & post \\
\hline Not as difficult as we had heard & difficulty & post \\
\hline $\begin{array}{l}\text { Statistics isn't easy; learning context can make it } \\
\text { harder }\end{array}$ & difficulty & post \\
\hline
\end{tabular}


Also in contrast to their comments reflecting an initial lack of first-hand experience with statistics, many post-course comments referenced cognitive and intellectual skills involved in learning statistics and the perceived importance (or lack thereof) of statistics in both personal and professional life. Student attitudes not only seem to be improving but also seem to be increasing in specificity. Specifically, with experience in the course, attitudes seem to show increased reflection on statistics itself, rather than vague feelings (fear of failure) or notions (it is a difficult subject). This increased specificity is particularly evident in many of the students' comments reflecting the cognitive competence and value dimensions, respectively. For example, see the comment from A' quoted above.

Interestingly, one of Gal and Ginsburg's (1994) criticisms of many of the quantitative, Likert-scale based student attitude measures is that students' scores on these measures may not reflect actual attitudes toward statistics itself but rather attitudes toward many other possible domains, such as mathematics in general or general self-confidence. The results of the qualitative study provide useful information that can help contextualize the results of the quantitative (SATS) study. For example, according to the quantitative measures, student attitudes significantly improved on three dimensions (affective, cognitive competence, and value) but not in student assessment of the difficulty of the subject. What can the qualitative data add to this picture?

It may be particularly useful to consider the affect and difficulty dimensions. The qualitative data paint a clear picture of student attitudes prior to the support course; with little first-hand experience of statistics, these students' attitudes were shaped almost entirely by the negative experiences of their peers. That is, they were filled with fear of failing, and they believed that statistics is a very difficult subject. The quantitative results show that attitudes on the affective dimension (including fear and other emotions) had a very large improvement from before to after the support course (the largest increase of all the dimensions). Interestingly, however, scores on the difficulty dimension were statistically stable. The details that emerge from the interviews suggest that, while students continued to consider the subject difficult, the successes they experienced during the course had a profound impact on their self-confidence and their affective experience in the course.

Additional comments from the interviewees address attitudes not only toward statistics but also toward the support course itself, as well as its capacity to influence students' experience of statistics. Indeed, many comments reflect the positive impact that the support course had on their attitudes toward the subject. For example, $C^{\prime}$ described her feelings:

...statistics isn't easy, and if you learn in a regular class with a teacher who doesn't take time to go over explanations, the subject can seem even harder. In the support course, you know in advance that the course is structured to suit students with LD, and this alone reduces the level of difficulty."

The third research question engaged in this study aims to explore which pedagogical components of the support course the students' perceived as 
especially supportive to learning statistics. As described in the Methods section, the support course instructor designed the support course around research-based pedagogical recommendations for statistics and LD/ADHD instruction as well as his own experience. As a result, it was interesting to explore which pedagogical components the at-risk post-secondary students perceived as most helpful to support their learning.

When asked whether their learning benefitted from the program, all of the interviewees responded in the affirmative. One of the interview questions indirectly addressed this subject by asking whether participating in the program is likely to improve students' positive feelings regarding statistics. Nine of the ten students agreed that the program supported a positive learning experience. In addition, nine of the ten students indicated in their answers specific pedagogical components that were unique to the program and that they perceived as supportive of statistics learning. The components that the students indicated can be divided into three categories:

1. Instructional components: using real life examples, breaking down complicated questions into smaller stages, practicing concepts with many questions and solving problems together in class.

2. Classroom components: small class size, peer support, cooperation among peers at similar levels of ability, being with students that experience similar challenges.

3. Student-instructor interaction: supportive and caring interactions, immediate response to questions whenever they arise, face-to-face classroom instruction unlike the standard online course; availability of the instructor to answer questions via email and phone whenever needed; confidence that there is someone who can address questions on a weekly basis.

In summary, a very common view expressed in the interviews was that the students' attitude toward statistics changed. Likewise, many interviewees mentioned that they thought the teaching methods were particularly suitable to the needs of students with learning disability: in particular, the opportunities for small group learning, the appropriate pace of instruction, the hands-on instruction, and the presentation of concrete examples and exercises from everyday life addressed their particular needs.

\section{Discussion and Conclusions}

The National Research Council (2000) identifies four principles to promote learning. First, learning environments must be learner-centered. Second, teachers should foster a knowledge-centered environment. Third, teachers should employ formative assessments- “ongoing assessments designed to make students' thinking visible to both teachers and students” (p. 24). Fourth, teachers should strive to create a community-centered environment that emphasizes the practice of learning from one another as vital to the learning process. While these ideals are relevant for teaching in general, the support course described here applied them to the particular needs of LD/ADHD 
learners. In line with this previous research, the at-risk students who participated in the current study indicated appreciation for components, approaches, methods and strategies that exemplify each of these four principles.

Before discussing implications of this work for teaching statistics to LD and ADHD student populations, we should consider several limitations inherent to this study and how they might affect the interpretation of the results. As noted above, institutional commitment to providing support services to LD and ADHD students proscribes a true experimental design. While we believe observed gains followed from the research-based teaching and course-design built into the support course, we recognize alternative interpretations. It may be that students like ours naturally improve on the SATS dimensions when exposed to a statistics course of any kind. Alternatively, it may have been the small-class setting or the presence of an instructor (or this particular instructor) in the room that yielded positive results. Indeed, it is possible that any or all of these caused the observed change in attitudes and that the specific design elements of the support course played no part at all. While that interpretation cannot be completely ruled out, we have good reason to believe the gains seen in the data flow from the course design itself. First, the design principles were drawn from an extensive literature; these were not random teaching methods. Moreover, when asked to identify effective course elements, participants named the very practices we believe led to their success.

With these caveats explicitly stated, we believe this study suggests several important principles for those teaching statistics in general and to the LD/ADHD subpopulation in particular. The study of support for students with special needs in higher education is a relatively new field, and few support models have been developed to date. The application of this model to this particular population is unprecedented. Likewise, the study of support in the learning of statistics is itself a relatively new field and thus the body of research is quite limited. The present initial-stage study offers a novel assessment of a current support course model applied to LD students in higher education.

The findings of this study should increase awareness of the special needs of students with LD and/or ADHD in institutions of higher learning in general, and teaching colleges in particular. This preliminary study evaluated a group model of support. There are several advantages of this model over the one-onone consultation model. The support course model provides systemic group support for students, rather than individual consultation, and the current study highlights its potential effectiveness regarding the improvement of academic attitudes among at-risk students. Students articulated the academic and emotional advantages of the group, including the fact that it functioned as a support group of peers in which they felt comfortable asking questions, knowing that all the participants were facing similar challenges. This 
advantage is unique to the group setting and cannot be part of the one-on-one consultation support model.

Second, the study demonstrates the possible importance of taking into consideration students' attitudes toward statistics, especially those of at-risk post-secondary students such as those with LD and/or ADHD. Post-secondary educational institutions, instructors, support centers and learning centers should take these principles into consideration, especially when teaching atrisk students such as those with $\mathrm{LD}$ and/or ADHD in courses that are considered particularly challenging. The results of the current study may suggest that evidence-based principles should be part of the pedagogical principles when teaching statistics at the post-secondary level in general. The support model that was examined, in combination with these principles, can effect change in the academic attitudes of at-risk students

Finally, even before they arrive in a statistics classroom, students may develop anxiety toward statistics, fear that it is a difficult subject, and a belief that statistics is not useful in their lives, which can negatively influence motivation to develop statistics competence (Gal, et al. 1997; Schau et al.2012). While all students will likely struggle under the burden of low selfconfidence, this problem is especially important when teaching the subpopulation of LD and/or ADHD students who have likely encountered significant educational challenges in the past. Evidence in this study suggests that designing support systems that address such affective factors can be a key factor in student success.

\section{Acknowledgments}

We would like to thank Avital Rachmilevich for assisting with data analyses and editing of the current paper.

\section{References}

Ben-Zvi, Dani and Joan Garfield. 2010. "Introducing the Emerging Discipline of Statistics Education.” School Science and Mathematics 108 (8): 35561. http://dx.doi.org/10.1111/j.1949-8594.2008.tb17850.x

Bond, Marjorie E., Susan N. Perkins, and Caroline Ramirez. 2012. "Students' Perceptions of Statistics: An Exploration of Attitudes, Conceptualizations, and Content Knowledge of Statistics.” Statistics Education Research Journal 11 (2): 6-25.

Butler, R. S. 1998. On the Failure of the Widespread Use of Statistics. Amstat News, Alexandria, VA: American Statistical Association.

Chiesi, Francesca, and Caterina Primi. 2009. "Assessing statistics attitudes among college students: Psychometric properties of the Italian version of the Survey of Attitudes toward Statistics (SATS)." Learning and

Individual Differences 19 (2): 309-13. http://dx.doi.org/10.1016/j.lindif.2008.10.008 
Eccles, Jacquelynne S., T. F. Adler, R. Futterman, S. B.Goff ,C. M.Kaczala, , J. L. Meece, and C. Midgley. 1983. "Expectancies, Values, and Academic Behaviors.” In Achievement and Achievement Motivation, ed. J. T. Spence, 75-146. San Francisco, W.J. Freeman.

Evans, Brian. 2007. "Student Attitudes, Conceptions, and Achievement in Introductory Undergraduate College Statistics.” The Mathematics Educator 17 (2): 24-30.

Finkelstein, Guy and Ariella Hellving. 2005. The Treatment of Students with Learning Disabilities within the Post-Secondary Framework (Hebrew). Status report presented to the Israel Council for Higher Education, April 2005. http://leshem.telhai.ac.il/index.html

Fuchs, Lynn S., Douglas Fuchs, Donald L. Compton, Sarah R. Powell, Pamela M. Seethaler, Andrea M. Capizzi, and J. M. Fletcher. 2006. “The Cognitive Correlates of Third-Grade Skill in Arithmetic, Algorithmic Computation, and Arithmetic Word Problems.” Journal of Educational Psychology 98: 29-43.http://dx.doi.org/10.1037/0022-0663.98.1.29

Gal, Iddo and Lynda Ginsburg. 1994. "The Role of Beliefs and Attitudes in Learning Statistics: Towards an Assessment Framework.” Journal of Statistics Education 2 (2): 1-15.

Gal, Iddo, Lynda Ginsburg, and Candace Schau. 1997. "Monitoring Attitudes and Beliefs in Statistics Education." In The Assessment Challenge in Statistics Education, eds. Iddo Gal and Joan B. Garfield, 37-51. Netherlands: IOS Press.

Garfield, Joan, Bob Hogg, Candace Schau, and Dex Whittinghill. 2002. "First Courses in Statistical Science: The Status of Educational Reform Efforts." Journal of Statistics Education 10 (2): 456-67.

Geary, David C., Carmen O. Hamson, and Mary K. Hoard. 2000. "Numerical and Arithmetical Cognition: A Longitudinal Study of Process and Concept Deficits in Children with Learning Disability." Journal of Experimental Child Psychology 77 (3): 236-63. http://dx.doi.org/10.1006/jecp.2000.2561

Gordon, Sue. 1995. "A Theoretical Approach to Understanding Learners of Statistics.” Journal of Statistics Education 3 (3): 1-21.

Klassen, Rob. 2002. "A Question of Calibration: A Review of the SelfEfficacy Beliefs of Students with Learning Disabilities.” Learning Disability Quarterly 25 (2): 88-102. http://dx.doi.org/10.2307/1511276

Liau, Albert K., John E. Kiat, and Youyan Nie. 2014.”Investigating the Pedagogical Approaches Related to Changes in Attitudes Toward Statistics in a Quantitative Methods Course for Psychology Undergraduate Students.” The Asia-Pacific Education Researcher 24 (2): 319-27.http://dx.doi.org/10.1007/s40299-014-0182-5

Multon, Karen D., Steven D. Brown, and Robert W. Lent. 1991. "Relation of Self-Efficacy Beliefs to Academic Outcomes: A Meta-Analytic Investigation.” Journal of Counseling Psychology 38 (1): 30-8 .http://dx.doi.org/10.1037/0022-0167.38.1.30 
National Research Council. 2000. How People Learn: Brain, Mind, Experience, and School. Washington, DC: National Academy Press.

National Research Council. 2005. How Students Learn: History, Mathematics, and Science in the Classroom. Washington, DC: National Academy Press.

Ruban, Lilia M., D. Betsy McCoach, Joan M. McGuire, and Sally M. Reis. 2003. "The Differential Impact of Academic Self-Regulatory Methods on Academic Achievement among University Students with and without Learning Disabilities.” Journal of Learning Disabilities 36 (3): 270-86. http://dx.doi.org/10.1177/002221940303600306

Schau, Candace, Joseph Stevens, Thomas L. Dauphinee, and Ann Del Vecchio. 1995. "The Development and Validation of the Survey of Attitudes Toward Statistics.” Educational and Psychological Measurement 55: 868-75. http://dx.doi.org/10.1177/0013164495055005022

Schau, Candace, Michelle Millar, and Peter Petocz. 2012. "Research on Attitudes toward Statistics.” Statistics Education Research Journal 11 (2): $2-5$.

Tabassam, Waheeda and Jessica Grainger. 2002. "Self-Concept, Attributional Style and Self-Efficacy Beliefs of Students with Learning Disabilities with and without Attention-Deficit Hyperactivity Disorder.” Learning Disability Quarterly 25 (2): 141-51. http://dx.doi.org/10.2307/1511280 van Garderen, Delinda. 2006. "Spatial Visualization, Visual Imagery, and Mathematical Problem-Solving of Students with Varying Abilities.” Journal of Learning Disabilities 39: 496-506. http://dx.doi.org/10.1177/00222194060390060201

Wolanin, Thomas R. and Patricia E. Steele. 2004. Higher Education Opportunities for Students with Learning Disabilities: A Primer for Policymakers. Report of the Institute for Higher Education, June 2004. 